\title{
Prototypes of risk-based flood forecasting systems in the Netherlands and Italy
}

\author{
D. Bachmann ${ }^{\text {a }}$, D. Eilander, A. de Leeuw, K. de Bruijn, F. Diermanse, A. Weerts, J. Beckers
}

Deltares, Boussinesqweg 1, 2629 HV Delft, The Netherlands

\begin{abstract}
Flood forecasting, warning and emergency response are important components of flood management. Currently, the model-based prediction of discharge and/or water level in a river is common practice for operational flood forecasting. Based on the prediction of these values decisions about specific emergency measures are made within emergency response. However, the information provided for decision support is often restricted to pure hydrological or hydraulic aspects of a flood. Information about weak sections within the flood defences, flood prone areas and assets at risk in the protected areas are rarely used in current early warning and response systems. This information is often available for strategic planning, but is not in an appropriate format for operational purposes. This paper presents the extension of existing flood forecasting systems with elements of strategic flood risk analysis, such as probabilistic failure analysis, two dimensional flood spreading simulation and the analysis of flood impacts and consequences. This paper presents the first results from two prototype applications of the new developed concept: The first prototype is applied to the Rotterdam area situated in the western part of the Netherlands. The second pilot study focusses on a rural area between the cities of Mantua and Ferrara along the Po river (Italy).
\end{abstract}

\section{Introduction}

Modern flood risk management is based on the three principal strategies: prevention, protection and preparedness including flood forecasts, warning and emergency response ([1]). Flood forecasting and warning systems are non-structural measures to reduce the residual flood risk by reducing the flood related impacts by timely and effective warning for an emergency response ([2]). Within the emergency response a specific warning is converted into specific measures ([3]). Adapted reservoir operation, enforcing existing flood defences by temporary measures or building new temporary flood defences, temporary object protection and horizontal or vertical evacuation of persons and assets are some examples of operationally available flood risk reduction measures (emergency measures). The added value of early warning/forecasting systems within disaster management is stated in [4]: early warning systems are important investments to protect and save lives, properties and livelihood.

In recent years model-based flood forecasting systems have been established all over the world for different spatial scales. In general, these model-based forecasting systems include a process chain starting with a meteorological model predicting the amount and spatial distribution of precipitation, wind and temperature over time, followed by a hydrological model which transfers the meteorological output data into hydrological data; mainly discharges in rivers (see Figure 1).

\footnotetext{
${ }^{\mathrm{a}}$ Corresponding author: Daniel.Bachmann@deltares.nl
}

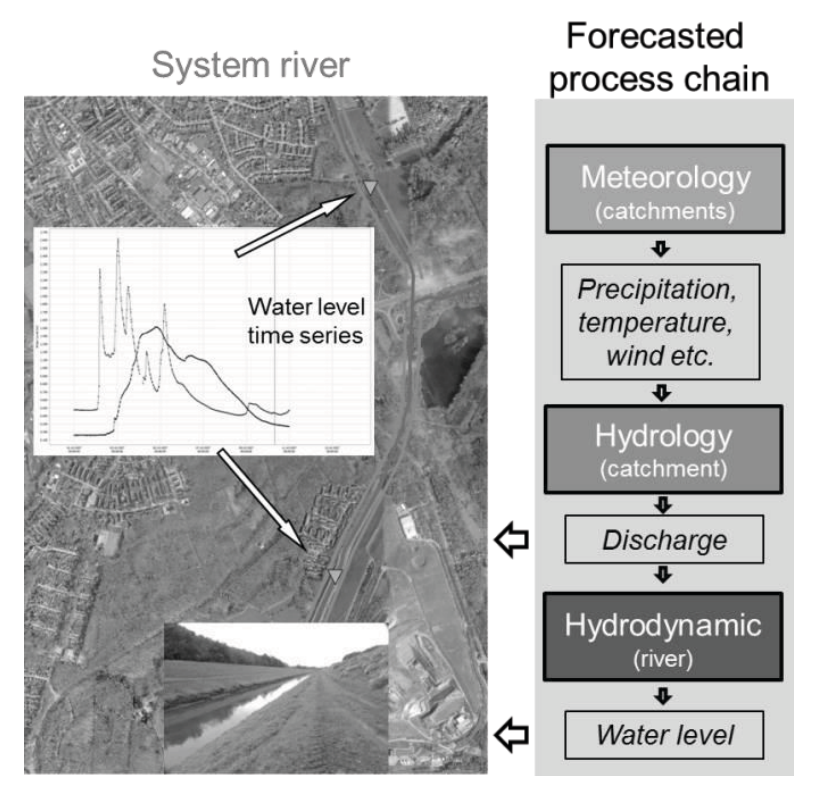

Figure 1. Current application of model-based flood forecasting: from meteorological forecast to a water level forecast

In some cases a next step in the process chain, the transfer of discharge into water level by a hydrodynamic model, is applied.

However, the hydrological/hydrodynamic-based information alone barely supports answering crucial questions within an emergency response framework, such as: 
- Where and when is a failure of my flood defence system possible?

- Where and when should I reinforce my flood defence system?

- What are the consequences and impacts of an overflow or a breach?

- Which areas should I evacuate first and how can I evacuate most effectively?

Currently, these questions are answered based on expert knowledge and/or - if available - pre-calculated information (e.g. about dike performance or flood spreading behaviour in the area).

With increasing data availability and computational resources combined with new modelling approaches and visualisation techniques, advanced forecasting information based on models gets more practicable. Fast data access to objective information, which can be adapted to the predicted situation can be provided. A few efforts of research have been made to fill the gap between model-based flood forecasting information and emergency response; [5] applied an extended flood forecasting system for the Mittlere Elbe in Germany, including meteorological, hydrological, and hydrodynamic models combined with a deterministic assessment of the dike performance. Also the EU-funded project URBANFLOOD ([6]) analysed and tested an extended process chain for flood forecasting by dike failure, breaching and flood spreading models. [7] applied a risk-based approach within a forecasting framework which combines the probability of the forecast and the level of impact of a flood event.

The presented concept is also based on extending the currently applied forecasted process chain (see Figure 1) by modelling techniques already applied and combined for several years in strategic risk assessment. These methods are probabilistic failure analysis, two dimensional flood spreading simulation and the analysis of flood impacts and consequences. Thus, additional model-based forecasting information is provided to the decision maker within an emergency response organisation, such as:

- Location, timing and probability of failure of defined sections of the flood defence line;

- Flood spreading, extent and hydraulic values in the protected area caused by an overflow or a breach flow;

- Impacts and consequences in case of flooding in the protected areas, such as potential injuries or casualties and/or damages to critical infrastructure or economy.

The additional model-based forecasting information gives answers to these questions. It supports the design of emergency measures (e.g. location, time, and type) and can effectively increase their leadtime. Moreover, the decision maker gets a broad overview of the prospective situation.

First this paper outlines the additional required workflows towards a risk-based flood forecasting system in general. Two subsequent workflows are presented: the first workflow deals with the performance of the flood defence line, the second one focusses on the impact of flooding. In cooperation between HR Wallingford (UK) and Deltares (NL), the extended workflows are being integrated into the Delft-FEWS software system which provides a generic shell for forecasting systems ([8]). Afterwards the results of two prototype applications for the Rotterdam area (The Netherlands) and the Po river (Italy) are presented. The value of the newly generated information for emergency response during a flood event is highlighted and discussed.

\section{Workflow 1: From a meteorological event to probability of failure}

The first workflow extends the currently applied forecasting workflow, which includes a meteorological to a hydrodynamic forecast (see Figure 1), by an assessment of the performance of the riverine or coastal flood defence line in case of a flood event. Therefore, the flood defence line is divided into sections. The performance including geotechnical and hydraulic aspects of each section is summarized in the fragility curve which provides a fast accessible and comprehensible format.

The fragility curve $F r c\left(h_{w}\right)$ expresses the reliability of a structure as a function of a defined dominant stress variable ([9]). In this context, the water level at the structure is defined as the dominant stress variable. The curve shows the conditional probability of the occurrence of a failure event $P$ (failure $\mid h_{w}$ ) [-] on the vertical axis as a function of the water level $h_{w}[\mathrm{~m}]$, represented on the horizontal axis (see Figure 2).

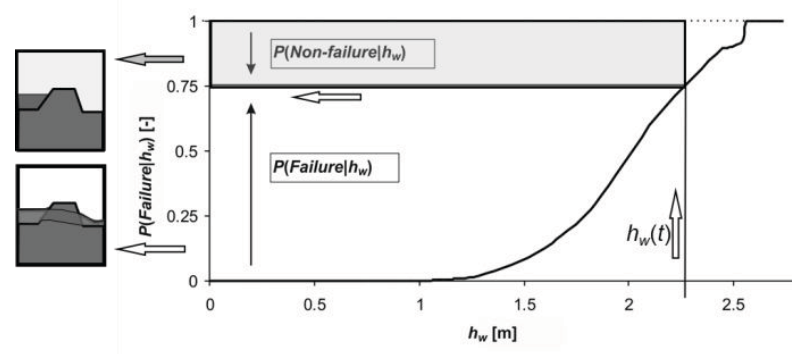

Figure 2. Concept of the fragility curve and the transformation from water level $h_{w}$ to probability of failure $P$ (failure $\left.\mid h w\right)$

The concept of the fragility curve was developed as part of the reliability analysis of engineering structures (e.g. [10]). According to [11] the application of fragility curves in flood management systems dates back to 1991 . Since that time further developments in the methods of determining fragility curves (e.g. [12]), the intrinsic level of detail (e.g. [13]) and their integration into flood risk assessment models ([14], [15], [16]) have been researched.

However, the application of fragility curves focusses mainly upon strategic flood risk assessment and the planning of flood protection measures. Trends show an increase in the application of fragility curves for assessing operational reliability ([11]). For example, [17] use pre-calculated fragility curves for 60 dike sections of the Emscher river to include also probabilistic aspects of dike failure into an operational flood forecast.

Within workflow 1 the determination of the fragility curves is done in advance (see Figure 3) assuming that 
the relevant input parameters are constant during a flood event. A fast access to the information is ensured. However, an update of the fragility during operational application gets necessary, if measured (e.g. by sensors in the dike) or observed (e.g. by dike inspectors) data are available or emergency measure have a direct influence to the dike performance (e.g. sand bags on the dike crest).

The forecasted water levels are transformed with the fragility curve for each section into a forecasted time series of failure probability $p_{f}[-]$ (see Figure 3 ). This transformation is performed for each water level $h_{w}$ (see Figure 2) over the forecasted time $t$.

The failure probability of a system $p_{\text {system, } f}[-]$ consisting of $n$ sections is determined with equation (1).

$$
p_{\text {system }, f}(t)=1-\prod_{i=1}^{i=n}\left(1-p_{f, i}(t)\right)
$$
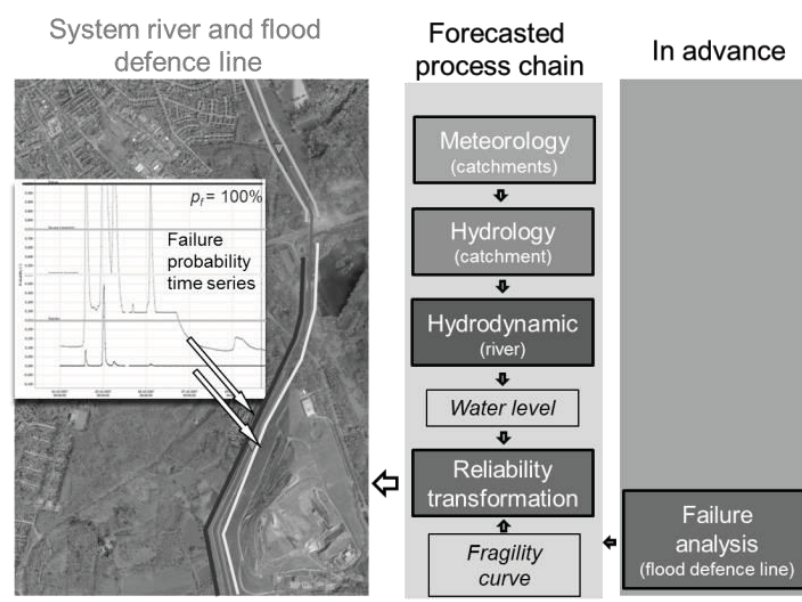

Figure 3. Integration of probabilistic failure analysis into the process chain by workflow 1 to represent the performance of the flood defence line

The generated results of workflow 1 provide information for the emergency response about the location, timing and probability of failure of defined sections of the flood defence line. With the help of this information emergency measures applied to the flood defence line (e.g. starting from increased inspection intervals up to temporary dike enforcements) can be operationally planned, adapted to the situation and triggered. Moreover, an overview of the forecasted status of the flood defence line is provided.

\section{Workflow 2: From failure to impacts}

The second workflow generates model-based forecasted information about flood impacts based on What-If scenarios: What happens if a breach occurs? These scenarios are user-defined. The generated information of workflow 1 provides valuable data to derive these scenarios.

The process chain is further extended by the following processes to get model-based forecasting information about probable impacts of a flood due to breach or an overflow (see Figure 4):

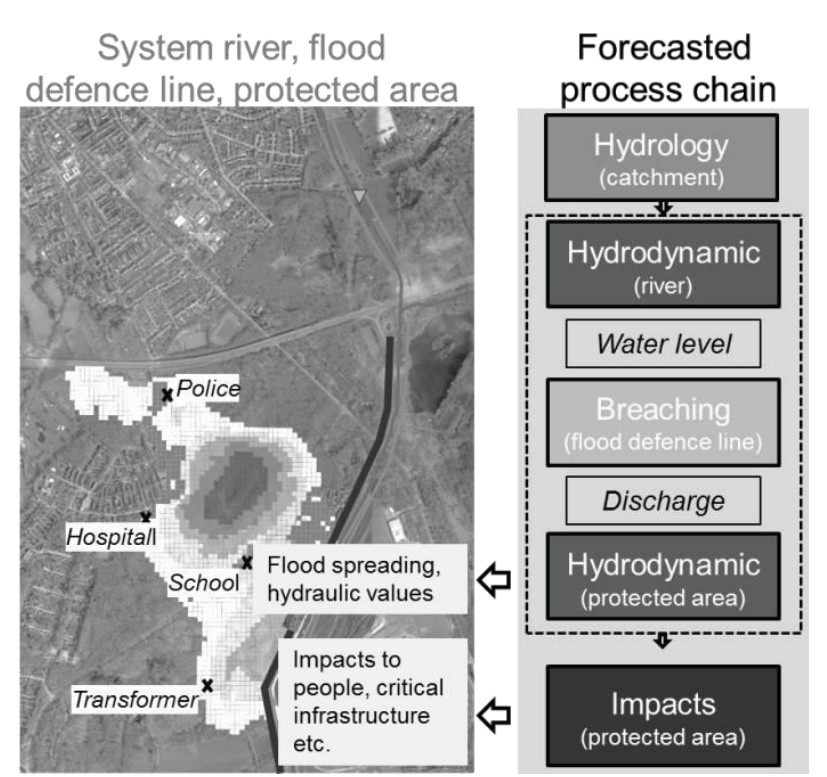

Figure 4. Integration of breaching, flood spreading and impact analysis into the process chain by workflow 2 to provide model-

based forecasted information about the impacts of flooding

The objective of the hydrodynamic analysis is the transformation of the forecasted hydrological boundary conditions into hydraulic values, such as water levels or flow velocities, taking into account the morphological characteristics of the river and protected area as well as the status of the flood defence line (failure or nonfailure). The breach analysis models the breach growth in width and depth depending on the hydraulic potential (the difference between the outside and inside water levels) as the main driving force compared to the resistance described by geometrical and geotechnical characteristics of a dike.

To keep the concept as flexible as possible, various sets of models and their couplings are applicable in a model-based forecasting framework. However, two requirements must be stated: firstly an unsteady hydrodynamic approach is required to model timedependent flood spreading; secondly the flood spreading in the protected area should be based on a two dimensional approach.

The objective of the impact analysis is the conversion of the hydraulic variables of a flood, like water levels and flow velocities, into consequences for people, assets and goods located in the affected areas.

Within strategic flood risk management the impact analysis is in general based on a quantitative assessment.

In an operational application a qualitative assessment of impacts via visualisation is often adequate. The qualitative assessment of impacts is based on intercepting the flood spreading with spatial data about impact potential in the protected area. These spatial data provides information about densely populated areas, land use and critical infra-structure, such as fire or police departments, schools and hospitals, cultural monuments or waste disposal areas.

The generated results of workflow 2 provide information for the emergency response about the flood spreading, such as time and distribution of flooding, flow velocities and water depth, and the resulting impacts to 
people and assets. With the help of this information emergency measures within the protected area (e.g. horizontal or vertical evacuation of people and assets, temporally object protection) can be operationally planned, adapted and triggered.

\section{Prototype application Rotterdam}

\subsection{Introduction}

The area of Rotterdam is located in the western part of the Netherlands (see Figure 5). Approximately 1.3 million people live in the greater Rotterdam area with an average population density of about 3000 Inhabitants $/ \mathrm{km}^{2}$. Housing, industrial and agricultural purposes are the predominant land use.

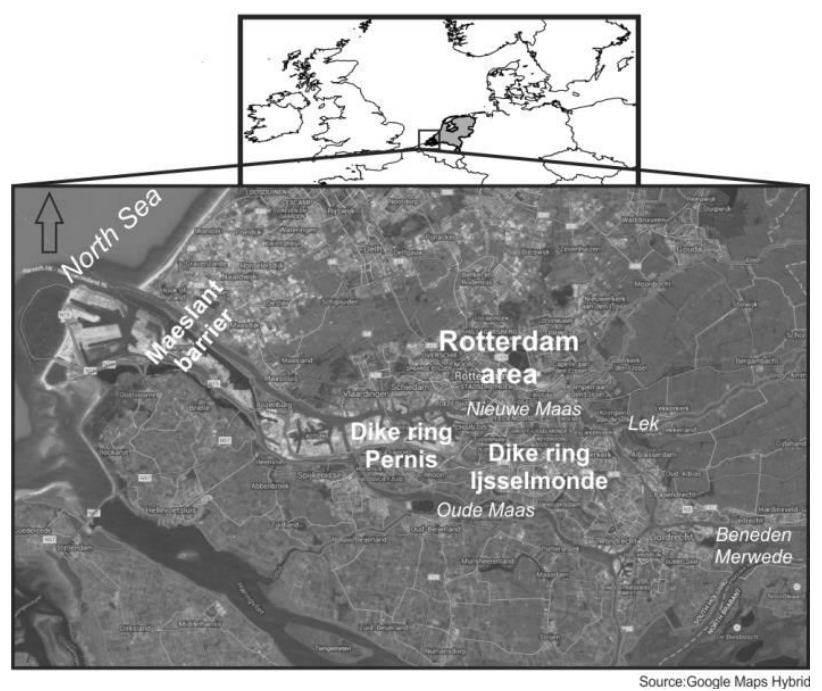

Figure 5. Prototype application Rotterdam area

Rotterdam is situated at the delta of the Rhine and Maas rivers, about $35 \mathrm{~km}$ from the North Sea. Due to this location in a deltaic area and an average elevation of $0 \mathrm{~m}$ NAP (Normal Amsterdam level), Rotterdam is a highly flood prone area with a very high flood impact potential. Coastal and riverine floods or combined events are probable. However, huge technical flood protection structures, like the Maeslant Barrier which protects the Rhine Meuse Delta from the North Sea in case of extreme surges and the high protection standards for the Dutch dike rings (up to a 10.000 yearly flood event), reduce the flood risk to a low level in this area.

The main purpose of the presented prototype application is to show the added value for decision makers concerned with emergency response.

\subsection{Model set-up}

\subsubsection{Reliability analysis}

The dike rings under investigation are the dike rings Pernis and IJsselmonde which are in the southern part of the Rotterdam area (see Figure 5). Based on previous studies ([18]), 14 dike sections in dike ring IJsselmonde and one dike section in dike ring Pernis are considered in this demonstration case as potential breach locations (see Figure 6).

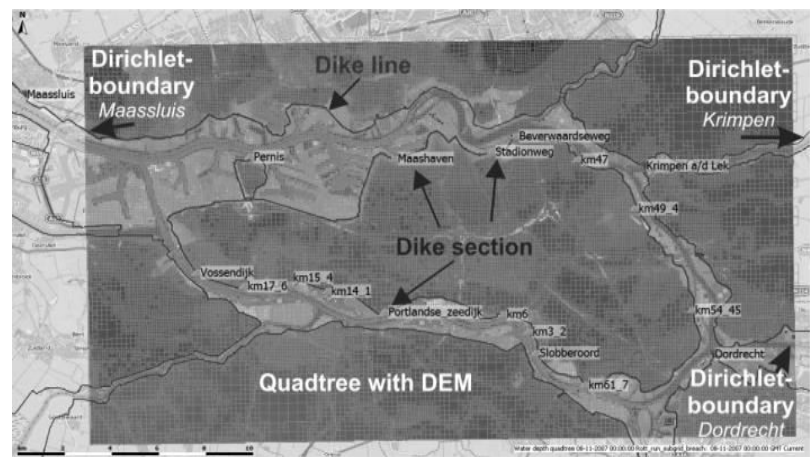

Figure 6. Considered dike section for a reliability analysis; Model set-up of the hydrodynamic model (Rotterdam area)

For these dike sections fragility curves are available ([18]), including three different failure mechanisms: overflow, piping and macro stability of the landward slope.

Figure 7 shows 3 calculated fragility curves for dike section km14_1, km47 and Pernis; for the sake of demonstration the dike sections km14_1 and $\mathrm{km} 47$ are manipulated (_man). For this demonstration case they now represent weaker dike sections than predetermined, shown in Figure 7 by a left shift of the fragility curves.

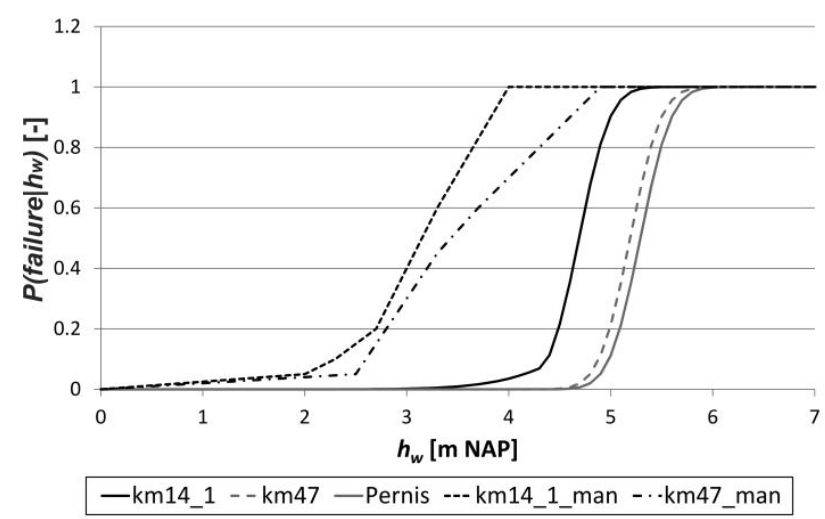

Figure 7. Probabilistic calculated fragility curves of three (out of 15) selected dike sections; manipulated fragility curves (_man) for dike section km14_1 and km47

\subsection{Hydrodynamic analysis}

For the hydrodynamic analysis the new simulation software 3di is applied, which has been developed by Deltares, together with consortium partners Delft University of Technology and Neelen \& Schuurmans. It solves the two-dimensional ST.-VENANT equation based on a quadtree raster. For each quadtree element underlying subgrid elements are defined to integrate an elevation model with higher resolution ([19]).

The two-dimensional model domain for the hydrodynamic model covers about $500 \mathrm{~km}^{2}$. The dike rings of Pernis and Ijsselmonde are completely inside the model domain (see Figure 6). To include also the surrounding rivers of the dike rings (see Figure 6) the model the area is extended beyond the dike rings. Thus, interactions (e.g. back water effects) between rivers and floodplains are represented in the hydrodynamic model. 
The model area consists of in total 40.000 quad-tree elements. Their resolution reaches from $100 \times 100 \mathrm{~m}$ to $400 \times 400 \mathrm{~m}$ according to the variability of the elevation within the quad-tree elements. The underlying subgrid raster has a resolution of $25 \times 25 \mathrm{~m}$. The dike lines of each dike ring are modelled by one-dimensional elements.

In the time domain $3000 \mathrm{~min}(50 \mathrm{~h})$ real time starting from 8/11/2007 0:00 are modelled (see Figure 8) at a oneminute time step. As initial condition a water level of 0.0 m NAP (Normal Amsterdam level) is applied in the river areas (outside the dike lines), the remaining areas are assumed to be dry.

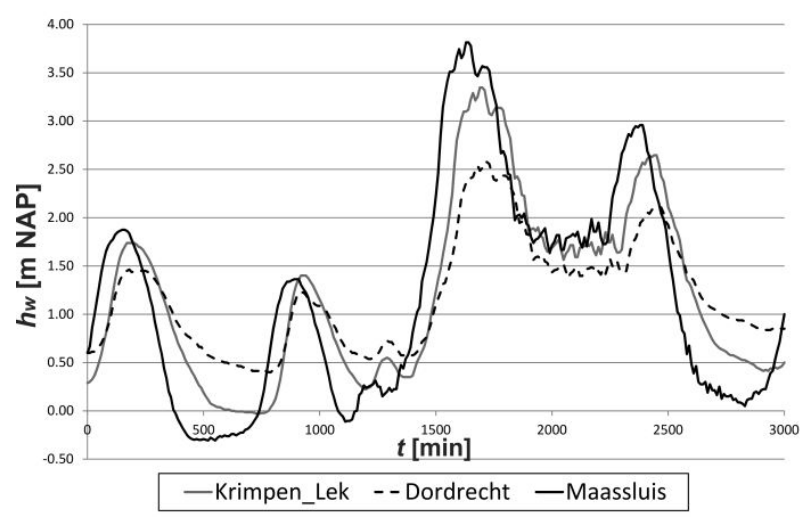

Figure 8. Hydraulic boundary condition (Dirichlet-boundary) of three different gauges

Dirichlet-boundaries (water level) are applied as boundary conditions at the gauge stations Maassluis, Krimpen and Dordrecht (see Figure 6). The time series are based on the historically measured water levels during the storm surge event in November 2007. In reality the Maeslant Barrier was closed during this event. The Rotterdam area was well-protected. However, here it is assumed (for demonstration purpose) that the barrier is not closed. The 2007 measured time series from the gauge station of Hoek van Holland which is outside the protected area and fully influenced by the North Sea is transferred with a statistical correlation approach to the three boundary gauge stations. Moreover, the derived water levels are multiplied by 1.25 to model a more severe storm surge event. The resulting water level time series are shown in Figure 8. The remaining boundary is assumed as no-flow boundary.

The applied time series are based on historical data, but real-time and forecasted data e.g. resulting from a storm surge or a hydrological model (see Figure 3) can easily replace them.

\subsubsection{Impact analysis}

For the impact analysis a pure qualitative approach is applied. Therefore, the model set-up consists primarily in the supply of spatial data like (see Figure 9):

- Spatial distribution of the population density to identify highly populated areas (dark shaded areas).

- Spatial distribution of critical objects; four subcategories are applied which are: Public buildings (e.g. fire and police department, town hall, shelter), cultural areas (e.g. Monument, museum), buildings housing highly vulnerable persons (e.g. school, hospital, kindergarten) and ecological perilous sites (e.g. waste water treatment, waste disposal).

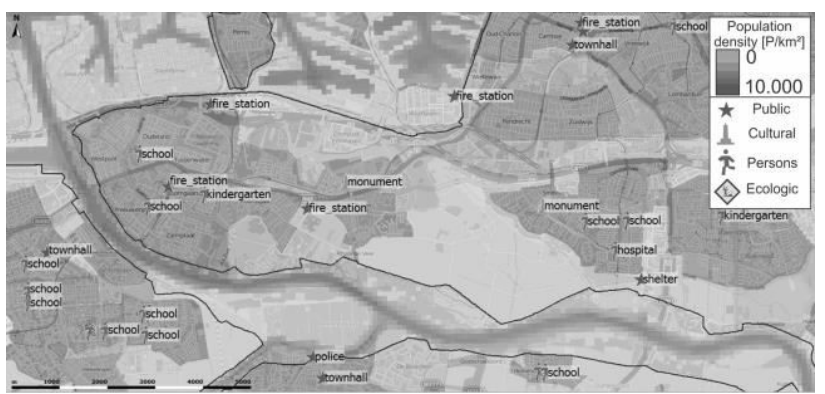

Figure 9. Data for a qualitative impact assessment; population density and critical infrastructure (Delft-FEWS display)

\subsection{Results of workflow 1}

Three water level time series (e.g. historical or predicted data) at Maassluis, Krimpen and Dordrecht (see Figure 6) are the boundary conditions for the hydrodynamic model. It is assumed that no dike failure and no breach development occur.

The first model run of the hydrodynamic model results in simulated water level time series at the 15 selected dike sections shown in Figure 6. One run of the hydrodynamic sub-grid model requires on an $\operatorname{Intel}(\mathrm{R})$ Core i5-3230M CPU $2.60 \mathrm{GHz}$ processor about $45 \mathrm{~min}$. The computational time seems to be adequate also for an operational purpose.

In the next step the water level time series are transformed according to the in pre-determined fragility curves at each dike section to a failure probability time series. The failure probability time series are further analysed according to a threshold exceedance in the considered time interval and warnings are triggered (see Figure 10). In this case, the following warning thresholds are applied to the failure probability of each dike section:

- 0.25: Increase inspection; adapt the time interval and the level of detail of dike inspections

- 0.50: Severe inspection; adapt the time interval and the level of detail of dike inspections; prepare emergency measures

- 0.75 : Triggering emergency measures

However, these thresholds are suggestions; other implication of actions according to the thresholds has to be considered by the end-user.

In the upper part of Figure 10 the modelled water level time series for the 15 dike sections depending to the applied boundary conditions are shown. 


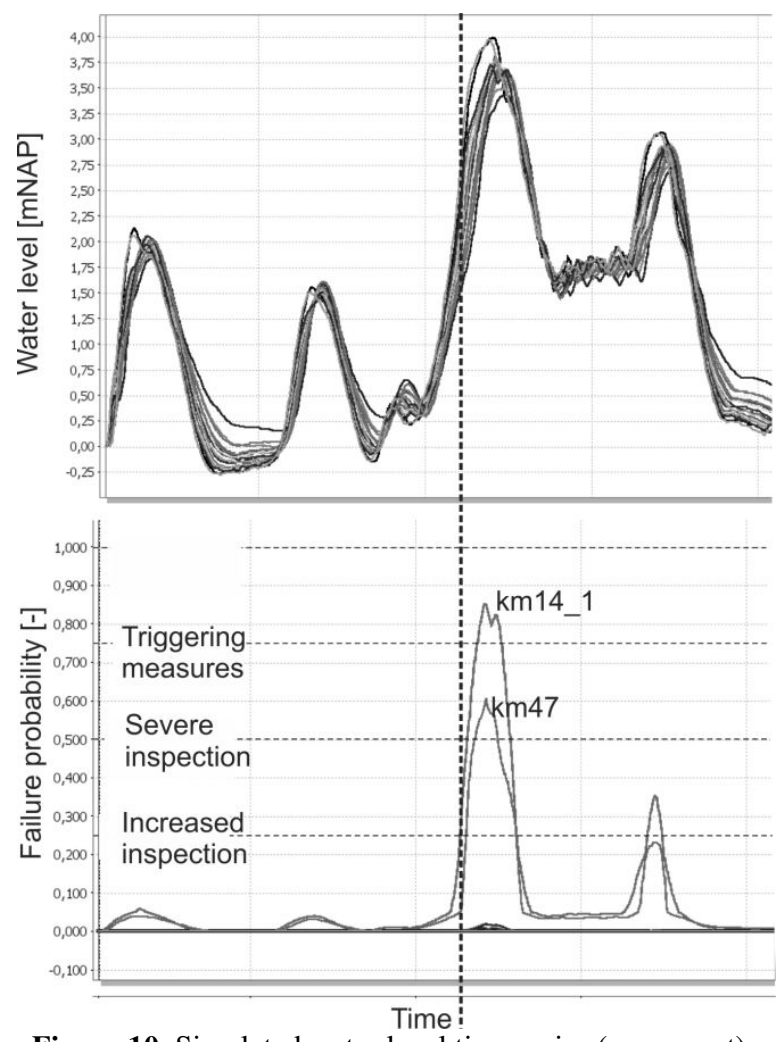

Figure 10. Simulated water level time series (upper part), corresponding failure probability time series (lower part) and threshold level (Delft-FEWS display) for the dike sections

The corresponding failure probability time series as a result of a transformation of the water levels with the fragility curves are represented in the lower part of Figure 10. The peaks of the water levels correspond to the peaks in the failure probabilities. A strong increase of the failure probability for the manipulated dike sections km47 and km14_1 starting by 9/11/2007 at 1:00 and an exceedance of the defined thresholds occurs. Dike inspectors can be warned with an extended lead time and deployed to the endangered sections. Emergency measures (e.g. sandbags) can be prepared.

\subsection{Results of Workflow 2}

According to the time series of failure probability, the simulated water level time series and a user-defined probability threshold for each dike section a breach development is calculated. By exceeding the defined probability threshold a breach development is started in the dike section. The user can interactively change these thresholds to define different breach locations and starting times (what-if scenarios).

After the determination of the breach growth (e.g. instantaneous breaching, linear breaching or a semiempirical breach growth model after [20]) a second run of the hydrodynamic model is started. The water level boundary conditions and the calculated breach width development are taken into account. This results in a time and breach dependent flood spreading.

The time dependent flood spreading as a result of the second run of the hydrodynamic model (with breach development) is indicated in Figure 11 starting from 9/11/2007 00:00 (upper left) to 10/11/2007 00:00 (lower right). It provides an overview of the situation in case of a failure in dike section km14_1 and km47.

About two hours after the breaching at dike sections km14_1 and km47 has been started (at 05:00; upper right part) first flooded areas can be seen around these locations. The following time steps ( 9 hours and 21 hours after the start of breaching) are showing a wide inundated area due to the dike breach at km14_1. Most of the western parts of the dike ring are affected by flooding. The flooding due to a dike breach at $\mathrm{km} 47$ stays locally bounded. This can be explained by a depression close to the breach location.

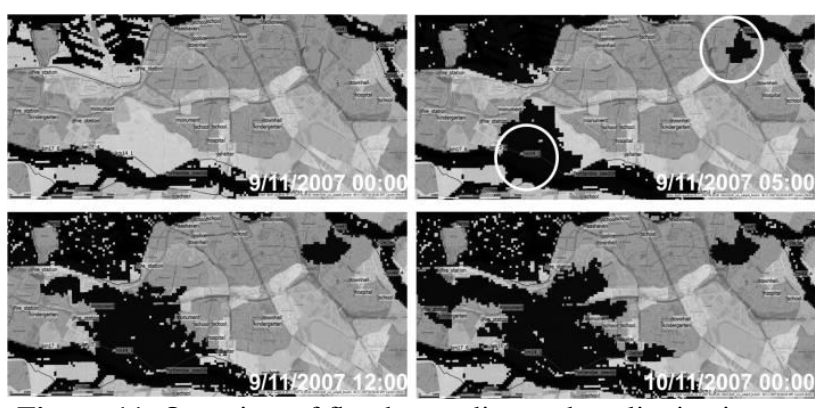

Figure 11: Overview of flood spreading and qualitative impact analysis for dike failure in km14_1 and km47 (Delft-FEWS display)

Figure 11 demonstrates the added value for the emergency response by overlaying the flood spreading with information about the population density and critical infrastructure (see Figure 9) within a qualitative impact analysis. Predicted model-based information about the time when and how a specific area is flooded and about the impacts in this area become available during an emergency event. This added value is confirmed by Figure 12, which depicts a detailed view to the flood extent caused by the breach at dike location km14_1. Besides the population density, the main streets, which could serve as evacuation routes, are presented. Figure 12 indicates that at 9/11/2007 05:30 the housing district with up to 4000 Inhabitants $/ \mathrm{km}^{2}$ nearby dike section $\mathrm{km} 14 \_1$ has been already partly flooded. The street N429 as a main evacuation route starts to be flooded at this time and will not be available anymore for an evacuation.

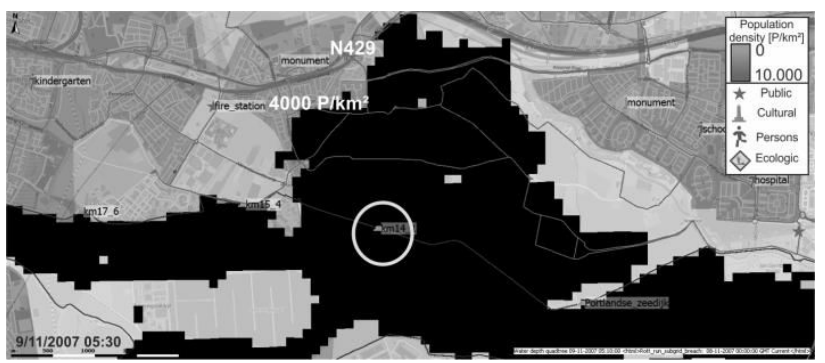

Figure 12. Detailed view to the flood spreading and the impacts (Delft-FEWS display)

\section{Prototype application Po river}

\subsection{Introduction}

The model area is located in the north eastern part of Italy (see Figure 13) at the Po river between the cities of 
Mantua and Ferrara. Agricultural purposes are the predominant land use. The average population density is about 100 Inhabitants $/ \mathrm{km}^{2}$.

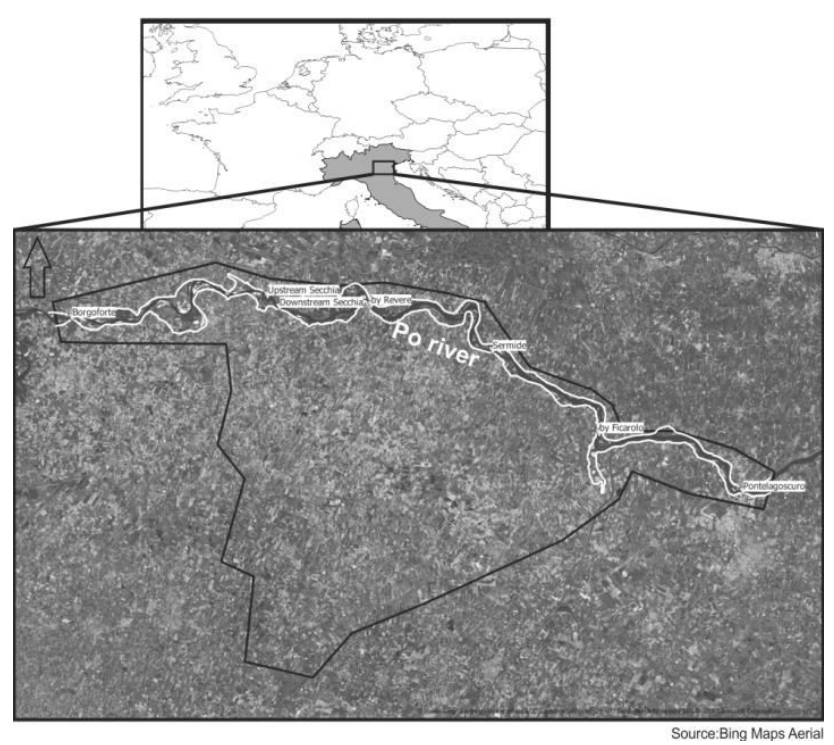

Figure 13. Prototype application Po river

The average height in the area varies from about 17 m.a.s.l. at the western boundary to 5 m.a.s.l. at the eastern part. Dikes with height up to $10 \mathrm{~m}$ along the Po river protect the adjacent area against flooding from the river. Additionally, several storage areas between the main river channel and main dike line are available for a reduction of the water level in case of a flood event.

In principle, the new information generated by the extended workflows and their added value presented for the prototype application of Rotterdam is quite similar for the prototype application of the Po river.

Thus, the focus in the following section is on the effect of water level reduction due to a dike failure and the added value of this information for emergency response. Other parts will be skipped. In the prototype application of Rotterdam almost no reduction of water level occurred due to a dike failure because of the mainly sea dominated water levels. In contrast to the Rotterdam area, only pluvial flood events occur in the application area of the Po river and the effect of water level reduction can be demonstrated.

\subsection{Model set-up}

The model set-up follows the presented set-up of the prototype application of Rotterdam. However, the data availability in terms of dike performance and consequences were less detailed.

\subsubsection{Reliability analysis}

Six dike sections were selected as potential breach locations (see Figure 14). They are all located at the right bank of the river (in flow direction) in the middle part of the model area.

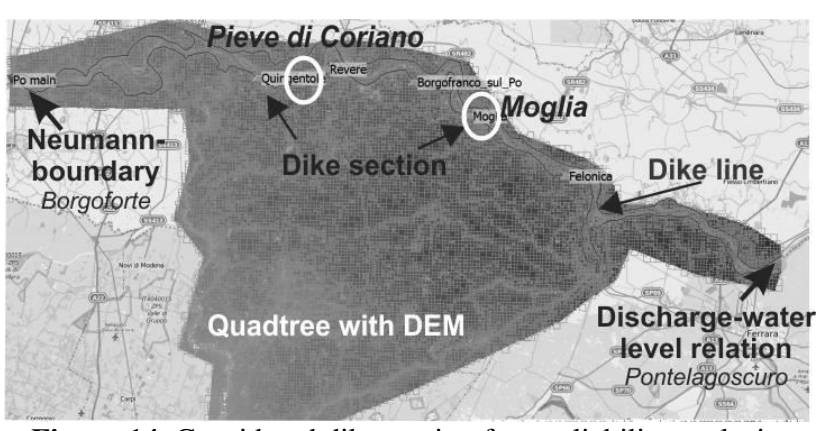

Figure 14. Considered dike section for a reliability analysis; Model set-up of the hydrodynamic model (Po river)

For these dike sections just the dike heights were available for this study. Based on these heights the fragility curves were assessed via expert judgement. Two points were fixed: starting by a failure probability $P\left(\right.$ failure $\left.\mid h_{w}\right)$ of 0.0 at the base point of the dike up to a failure probability $P\left(\right.$ failure $\left.\mid h_{w}\right)$ of 1.0 by reaching the dike crest height (see Figure 2). That means the dike will fail in case of an overflow event. Two points were set in between (taking geotechnical failure into account) which vary in terms of height and failure probability between the sections (demonstration purpose). The four points are linearly connected.

\subsubsection{Hydrodynamic analysis}

The two-dimensional hydrodynamic analysis is also performed with the $3 \mathrm{di}$ software package. The model domain covers about $1.300 \mathrm{~km}^{2}$. It includes about $85 \mathrm{~km}$ of the Po river as well as the adjacent area located in the South of the river (see Figure 14).

The model area consists of in total 40.000 quad-tree elements. Their resolution reaches from $144 \times 144 \mathrm{~m}$ to $576 \times 576 \mathrm{~m}$ according to the variability of the elevation within the quad-tree elements. The underlying subgrid raster has a resolution of $12 \times 12 \mathrm{~m}$. The dike lines along the river are modelled by one-dimensional elements.

In the time domain $216 \mathrm{~h}$ real time starting from 13/10/2000 0:00 are modelled in a two-minute time step. One run of the hydrodynamic sub-grid model requires on an Intel(R) Core i5-3230M CPU $2.60 \mathrm{GHz}$ processor about $90 \mathrm{~min}$.

A Neumann-boundary condition (discharge) is applied at the gauge stations Borgoforte (see Figure 14). The discharge time series is based on the flood event in October 2000. The peak discharge is about $12.000 \mathrm{~m}^{3} / \mathrm{s}$ around $150 \mathrm{~h}$ after start. The downstream boundary condition at Pontelagoscuro is modelled as dischargewater level relation derived from available simulated and measured data.

\subsection{Result of Workflow 2}

For all dike sections a probability threshold for starting a breach development of 0.5 is assumed. The threshold is exceeded at dike section Pieve di Coriano (see Figure 14) at 19/10/2000 19:30. A breach development starts. Other dike failures are not predicted.

The flood spreading after a dike failure at section Pieve di Coriano is shown in Figure 15 starting from 
19/10/2000 20:00 (upper left) to 20/10/2000 16:00 (lower right).

About 2.5 hours after the breaching at the dike section has been started (at 22:00; upper right part) flooded areas with a radius of about $3 \mathrm{~km}$ can be seen around the breach location. The following time steps (10.5 hours and 20.5 hours after the start of breaching) are showing that the flood spreading extends in direction south east along the river. In the southern and western direction it stays bounded. However, severe flooding is expected.

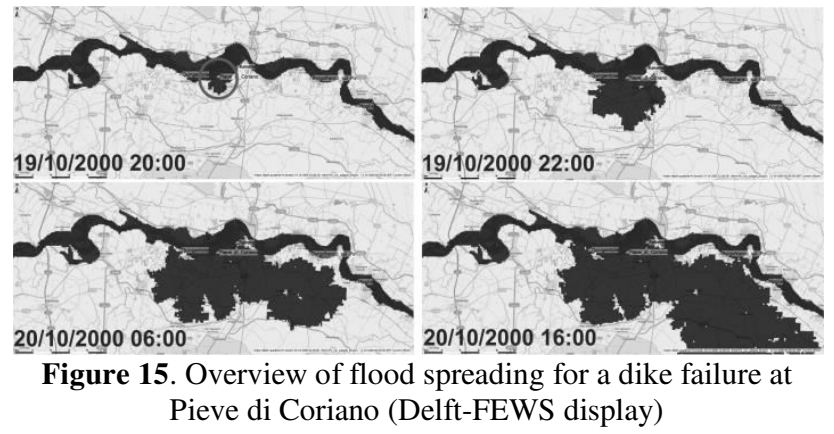

The effect of the dike failure to the water levels in the river is demonstrated by Figure 16. A water level reduction at Moglia (see Figure 14) - located about $20 \mathrm{~km}$ downstream of the breach location - from about $1.2 \mathrm{~m}$ is predicted. Even $50 \mathrm{~km}$ downstream the breach location a water level reduction of about $0.8 \mathrm{~m}$ is modelled.

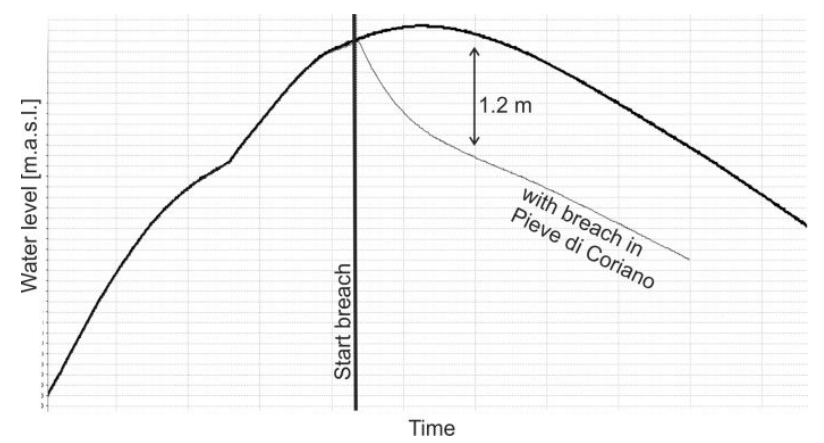

Figure 16. Water level reduction at dike section Moglia due to a dike failure in Pieve di Coriano

The reduced water level results in a reduced failure probability in the downstream section (see Figure 17). For example for the dike section Moglia a failure at Pieve di Coriano results in a reduction of the maximum failure probability of $0.1(10 \%)$.

These results show that a two-dimensional flood spreading model provides more reliable forecasted information in case of a dike failure or an extensive overflow event than a pure one-dimensional model. Water level reduction is predictable. The reduced water levels result in reduced stress on the downstream dike sections. Dike failure is less probable.

For the emergency response the forecasted, simulated information about how a system reacts in case of a dike failure is relevant. The forecasted time-dependent flood spreading in the protected area, but also the effect of water level reduction (resulting in a reduction of failure probability) to other dike sections supports the planning of emergency response measures. Forces can be drawn back at dike sections where the stress is reduced.
Moreover, the system is able to support the emergency planning of forced dike failure.

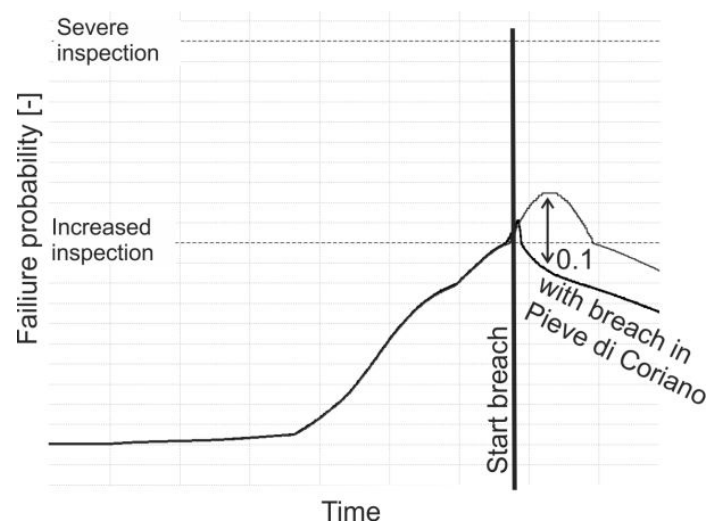

Figure 17. Failure probability reduction at dike section Moglia due to a dike failure in Pieve di Coriano

\section{Conclusion}

Flood forecasting, warning and emergency response are important non-structural measures to reduce the residual flood risk. An extended flood forecasting system is presented to provide emergency response organisation model-based forecasting information about the performance of the flood defence, flood spreading and resulting flood impacts to people and critical infrastructure. Probabilistic failure analysis resulting in fragility curves, two dimensional hydrodynamic simulations and qualitative impact assessment is used to generate advanced information for emergency response organisation.

The developed concept is applied to the Rotterdam area and the Po river area as first prototypes of the system. They demonstrate the added value for emergency response organisation. The first workflow provides model-based forecasted information about the performance of the flood defence line; the second workflow transfers the forecasted data into model-based forecasted flood spreading and impact information in case of a failure event. Forecasted information about water level reduction becomes also available. The additional generated information can effectively support the design and adaptation of emergency measures (e.g. location, time, and type) to the forecasted situation and can increase their leadtime.

The presented prototype applications are not yet used in an operational context by emergency response organisations. In a follow-up phase the concept needs to be implemented by responsible organisations, tested, evaluated and adapted according to their requests.

\section{Acknowledgement}

The development of the concept was funded by internal research budget of HR Wallingford and Deltares.

The presented prototype applications were part of the EU-funded FP7 RASOR project (Rapid analysis and spatialisation of risk). 
ARPA (Regional Environmental Protection Agency of Italy) provided data, information and comments to the prototype application Po river.

Special thanks to Emma Brown (HR Wallingford) who provided useful comments to the paper.

\section{References}

1. EU (2007): Directive of the European Parliament and of the Council on the assessment and management of flood risks (2007/60/EG); Brussels: Commission of the European Union; http://eur-lex.europa.eu/legalcontent/EN/TXT/PDF/?uri=CELEX:32007L0060\&fr om=EN; [Accessed: 06.03.2015].

2. Weerts, H. A., Schellekens, J. and Weiland, F. S. (2010): Real-Time Geospatial Data Handling and Forecasting: Examples from Delft-FEWS Forecasting Platform/System. In: Journal of selected topics in applied earth observation and remote sensing, Vol. 3, No. 3, pp. 386-394. - ISSN 19391404.

3. Verkade, J. S. and Werner M. (2011): Estimating the benefits of single value and probability forecasting for flood warning. In: Hydrology and Earth System Science, Vol. 15, pp. 3751-3765. - ISSN 1027-5606.

4. UNISDR (2005): Hyogo Framework for Action 2005-2015 - Building the Resilience of Nations and Communities to Disasters; UNISDR (United Nations Office for Disaster Risk Reduction); http://www.unisdr.org/2005/wcdr/intergover/officialdoc/L-docs/Hyogo-framework-for-actionenglish.pdf; [Accessed: 17.05.2016].

5. Kron, A. and Nestmann, F. (2009): Operationelles Hochwassermanagement in großräumigen Extremsituationen am Beispiel der Mittleren Elbe. Final report for BMBF- research project. http://www.rimax-

hochwasser.de/fileadmin/user_uploads/RIMAX_PU B_

18_0005_Schlussbericht_BMBF_0330698B_end_09 1222+.pdf; [Accessed: 06.03.2015].

6. Krzhizhanovskaya, V. V., Shirshov, G. S.,Melnikova, N. B., Belleman, R. G., Rusadi, F. I., Broekhuijsen, B.J., Gouldby, B.P., Lhomme, J., Balis, B., Bubak, M., Pyayt, A. L., Mokhov, I. I., Ozhigin A. V., Lang B. and Meijer, R. J. (2011): Flood early warning system: design, implemen-tation and computational modules. In: Procedia Computer Science, Vol. 4, pp. 106-115. - ISSN 1877-0509.

7. Dale, M., Wicks, J., Mylne, K., Pappenberger, F., Laeger, S. and Taylor, S. (2014): Probabilistic flood forecasting and decision-making: an innovative riskbased approach. In: Natural Hazards, Vol. 70, pp. 159-172. - ISSN 0921-030X.

8. Werner, M., Schellekens, J., Gijbers, P., van Dijk, M., van den Akker, O. and Heynert, K. (2013): The Delft-FEWS flow forecasting system. In: Environmental Modelling \& Software, Vol. 40, pp. 65-77. - ISSN 1364-8152.

9. Hall, J., Dawson, R., Sayers, P., Rosu, C., Chatterton, J. U. and Deakin, R. (2003): A methodology for national-scale flood risk assessment. In: Water \& Maritime Engineering, Vol. 156, No. WM3, pp. 235-247. - ISSN 1472-4561.

10. Casciati, F. and Faravelli, L. (1991): Fragility Analysis of Complex Structural Systems, West Sussex (GB): John Wiley \& Sons Inc. - ISBN 086380-114-5.

11. Schultz, M., Gouldby, B., Simm, J. and Wibowo, J. (2010): Beyond the Factor of Safety: Developing Fragility Curves to Characterize System Reliability. ERDC SR 10 1. G. a. S. Laboratory, USACE.

12. Simm, J. Gouldby, B., Sayers, P., Flikweert, J.-J., Wersching, S. and Bramley, M. (2009): Representing fragility of flood and coastal defences: Getting into the detail. In: Flood Risk Management: Research and Practice / Samuels et al. London (GB): Taylor \& Francis Group, - ISBN 978-0-415-48507-4.

13. van der Meer, J. W., ter Horst, W. L. A. and van Velzen, E. H. (2009): Calculation of fragility curves for flood defence assets. In: Flood Risk Management: Research and Practice / Samuels et al. London (GB): Taylor \& Francis Group, - ISBN 9780-415-48507-4.

14. Vorogushyn, S., Merz, B., Lindenschmidt and K.-E., Apel, H. (2010): A new methodology for flood hazard assessment considering dike breaches. In: Water Resources Research, Vol. 46. - ISSN 00431397.

15. Bachmann, D. and Schüttrumpf, H. (2014): Integration der Zuverlässigkeit von Hochwasserschutzbauwerken in die einzugsgebietsbasierte Hochwasserrisikoanalyse. In: Hydrology and water resources management Germany, Vol. 58, No. 3, pp. 168-177. - ISSN 14391783.

16. Diermanse, F. L. M., De Bruijn, K. M., Beckers, J. V. L. and Kramer, N. L. (2015): Importance sampling for efficient modelling of hydraulic loads in the Rhine-Meuse delta. In: Stochastic Environmental Research and Risk Assessment, Vol. 29, Issue 3, pp. 637-652. - ISSN 1436-3240.

17. Bachmann, D., Johann, G., Huber, N.P and Schüttrumpf, H. (2013): Fragility curves in operational dike reliability assessment. - In: Georisk: Assessment and Management of Risk for Engineered Systems and Geohazards, 7:1, pp. 49-60.- ISSN 1749-9518.

18. van der Meij, R. (2013): Overhoogte in RijnmondDrechtsteden. Report Deltares 1207828-003.

19. Stelling, G. S. (2012): Quadtree flood simulations with subgrid digital elevation models. In: Water Management, Vol. 165, Issue WM10, pp. 567-580. ISSN 1751-7729.

20. Verheij, H. (2003): Aanpassen van het bresgroeimodel binnen HIS-OM. Report. DelftHydraulics, Delft (NL). 